\title{
Compassion As A Practical And Evolved Ethic For Conservation
}

Daniel Ramp ${ }^{1}$ and Marc Bekoff ${ }^{1,2}$

${ }^{1}$ Centre for Compassionate Conservation, School of the Environment, University of Technology Sydney, PO Box 123 Broadway, NSW, 2007, Australia

${ }^{2}$ Ecology and Evolutionary Biology, University of Colorado, Boulder, C0, 80309, USA

Corresponding author: Ramp, D. (daniel.ramp@uts.edu.au) 


\begin{abstract}
The ethical position underpinning decision-making is an important concern for conservation biologists when setting priorities for interventions. Recent debate on how best to protect nature has centered on contrasting intrinsic and aesthetic values against utilitarian and economic values, driven by an inevitable global rise in conservation conflicts. These discussions have primarily focused on species and ecosystems as their targets for success, without explicitly expressing concern for the intrinsic value and welfare of individual animals. In part, this is because animal welfare has historically been thought of as an impediment to conservation. However, practical implementations of conservation that provide good welfare outcomes for individuals are no longer conceptually challenging - they have become reality. This reality, included under the auspices of 'compassionate conservation', reflects an evolved ethic for sharing space with nature and is a major step forward for conservation.
\end{abstract}


Every day, environmental policy makers, conservation practitioners, and land managers, make decisions that affect the lives of wild animals. The societal norms that shape the context for those decisions are complex, entrenched, and often not transparent to the wider community. Despite the complexity, there is growing awareness that conservation decisions, particularly those aimed at resolving conflicts between humans and other animals but also conflicts between other animals, often result in the harming and death of other animals. That these animals carry the burden of achieving conservation objectives through their harm and death is often ignored or else justified on utilitarian grounds. It is common for some members of a single species to be killed for the 'good' of their species, or else members of one species are killed for the 'good' of another species (e.g. golden hamsters for black-footed ferrets) (Bekoff 2010). Animals are also routinely killed to prevent them from moving from protected areas to private land (e.g. wolves and dingoes) (Treves and Karanth 2003), and because they are considered to be invasive or 'pests' (Littin 2010). These trade-offs often result in harm and death for captive and wild animals, justified in the name of conservation and human benefit (Bekoff 2003, Ben-Ami et al. 2014, Callicott 1990). The question is where the trade-offs stop and the protection of individuals begins. How many individuals are acceptable to kill and harm in the name of conservation (Vucetich and Nelson 2007) and at what point does their well-being matter (Bekoff 2013)? Conservation practice and policy has historically addressed this question uncertainly and often without virtue (Vucetich and Nelson 2013). This has not been an easy question to resolve, primarily because the problem has not been with conservation itself, but rather the manner in which it has been performed. 
In turn, this situation can in part be attributed to the perceived difficulty in comparing complex and competing sets of values (e.g. individual rights and values versus ecosystem health), notions of human exceptionalism and dominance, and the overly strong focus on species welfare (as opposed to individual welfare) in conservation metrics. The result is that without consensus on how to accommodate what appear to be contradictory values, moral confusion and ethical dilemmas are common. Consequently, there has traditionally been a lack of animal welfare concern in conservation decision-making when addressing the stark, yet real, question, of 'who lives and who dies', in part due to past disagreements between conservation and animal welfare scientists on the role of individual welfare in conservation (e.g. Soulé 1985). Environmental legislation and policy is almost wholly grounded in measures of species and ecosystem welfare (Gaston and Fuller 2007), with little emphasis on individual welfare. In contrast, animal welfare legislation often has tight control over the individual welfare of domestic animals and livestock. Wild animals are frequently exempted from animal welfare legislation by categorizing them as 'pests', a term used to define a species that is a nuisance, out of balance, invasive or exotic (Nagy and Johnson 2013). Often, the issues faced by conservation managers are in relation to species that are placed in this category, and perhaps not coincidentally, transgressions of humane treatment are frequently justified by the application of this label (Littin 2010).

Language and culture are strongly linked to our treatment of other animals (Webb and Raffaelli 2008). Societal norms are often rendered with euphemisms to surmount the impression of transgressions of equity and justice, thus obscuring the obvious ethical conflict our actions cause. Bias in the selection of flagship species to protect, where flagship species are used to leverage support for broader conservation 
objectives, is a complex mix of charisma (Lorimer 2007, Tisdell and Nantha 2007) and politics (Yeo and Neo 2010). Animal protection is strongly influenced by prevailing views on sentience and cognition (Bekoff and Jamieson 1990), position on the phylogenetic scale (Harrop 1999), and utility to humans (O'Sullivan 2011). Of course, not all species can be saved from extinction, nor can all individuals be spared from dying or suffering needlessly at the hands of humans. But there is currently little deliberate ethical enquiry in how trade-offs in lives are made (Larson 2007), and little room for empathy (Bekoff 2013).

\section{Blockages in conservation decision making}

The focus on species welfare and anthropocentric views of nature has been an impediment to scientifically validating the inclusion of individual welfare in conservation. Although species welfare, with its focus on the prevention of extinction, is a vital and admirable conservation objective, the welfare of individuals and their social groups should also be considered as important. Harm to animals is more than just the extinction of species and subsequent declines in biodiversity. This awareness stems from the dramatic rise in human-wildlife conflicts (Redpath et al. 2013) and a growing recognition of the intrinsic value of conscious and sentient animals (Bekoff 2007, 2014). Harm also encompasses the suffering experienced by individuals and associated costs to social units and the populations to which they contribute (Fraser 1993, Paquet and Darimont 2010). While many of these harms result from global conservation problems such as habitat loss, climate change, and pollution, many harms paradoxically result from humans engaging in proactive conservation measures (Fraser and MacRae 2011).

Although clear and inclusive ethical foundations for conservation have been articulated numerous times, these foundations have been gradually eroded by human 
needs and benefits and prevailing views of human exceptionalism. Motivations for humans to engage in conservation encompass a wide variety of societal values; incorporating ethical, aesthetic and economic concerns (Doak et al. 2013). These oftencompeting values are increasingly resulting in conflict and present considerable philosophical, moral, and practical problems for conservation planners and policy makers. Conservation interventions require decision-makers to make trade-offs among philosophical and ethical value sets and practical limitations. Problematically, conflict resolution between conservation and other human endeavors is, more often than not, dictated by decision-making aimed at economic and utilitarian values (Artelle et al. 2014), to the detriment of aesthetic and other ethical values (Jepson and Canney 2003). The denial of the intrinsic value and sentience of non-human animals is also strongly influential. Despite having the protection of animals and conflict resolution at its heart, conservation science as a discipline has struggled to establish a strong environmental ethic and moral philosophy, to the detriment of individual animals.

\section{Conservation is ethically challenged}

Discourse surrounding the ethical position of conservation is not new (Dunlop 2006, Ehrlich 2002, 2009, Minteer and Collins 2005). Although the dominant paradigm governing conservation policy is based on a limited anthropocentric version of utilitarianism, which is a form of consequentialism, there are several other ethical positions with implications for conservation and animal protection, such as deontology (Regan 1983) and deep ecology (Naess 1973, Routley 1973) that reject the utilitarian view of the environment (i.e. the 'shallow' view). The importance of ethics in conservation was noted as part of the founding principles of the Wildlife Society in 1937 in the United States, where the "development of all types of wildlife management along 
sound biological lines" was seen as a crucial move away from indiscriminate exploitation for human benefits (Bennitt et al. 1937). Aldo Leopold further championed this idea in 1949 with his 'land ethic' (Leopold 1949). At that time, Leopold firmly embedded the sharing of land between humans and other animals in his land ethic, allowing for both the preservation of wilderness where possible and for economic exploitation (Callicott 1990). Importantly, the land ethic approach encompassed the view that individuals and their well-being mattered (Davradou and Namkoong 2001). The implementation of this ethic, however, has remained stymied by the more dominant anthropocentric utilitarian ethic that espouses decisions that promote overall well-being (actions for the greater good). Not only has exclusive concern for human benefits taken a strong hold of motivational mechanisms (e.g. as proposed in the 'new conservation') (Kareiva and Marvier 2012), but the grounding of conservation in species welfare has, perhaps unintentionally, subjugated individuals for collective benefits.

The challenge for conservation science is to decide whether current decision-making in practice and policy evolves to accommodate contemporary moral systems and incorporate the rapidly developing scientific understanding of the sentience and consciousness of nonhuman animals, or whether, at a practical level, the trumping of welfare outcomes for individual animals by species (or population or ecosystem) welfare or by human benefits continues to be permissible (Fraser 2012). Evidence from conservation policy suggests that this challenge is often sidestepped and that the status quo remains by default (Artelle et al. 2014). Why has this happened? Negativity towards individual welfare has become entrenched because it has been viewed an impediment to holistic decision-making. Dominant and entrenched values are maintained through 
individual and collective aspirations (Jepson and Canney 2003) and cultural norms and perceptions (Lejano and Fernandez de Castro 2013), while disengagement of moral selfsanctions allow for harmful practices by removing self-restraint (Bandura 2007). Entrenched views can have a significant and wide-ranging influence on conservation policy and decision-making, where vocal stakeholders often assert value-based rhetoric to the detriment of alternative value sets (e.g. Ramp 2013). This is evident in a wide variety of conservation issues that result in direct conflict between advocates of alternative positions (Redpath et al. 2013), but conversely can also drive efforts to alleviate conflicts via education programs and co-management strategies (e.g. Gelcich et al. 2008).

\section{Compassion in conservation}

The good news is that the asserted dichotomy between conservation and animal welfare has waned, and the unifying aim of reducing harm to non-human animals in both these disciplines has gathered momentum (Bekoff 2013, 2014, Fox and Bekoff 2011, Fraser 2010, Littin 2010, Paquet and Darimont 2010). The challenge has been for decision makers to establish a practical framework (i.e. one that is ideologically sound and able to be implemented through on-ground activities) that accommodates the ethical and moral position of individual animals within conservation practice (Bekoff 2002). In a case of widespread convergent evolution, examples of conservation initiatives aimed at achieving both conservation goals and reduced harm to individuals have emerged over the last few decades. Despite the dominant lethal paradigm underlying many conservation initiatives (Bergstrom et al. 2014), compassionate approaches to solving conflicts between humans and wildlife have evolved. These highlight the rise of what has been termed 'compassionate conservation' (Bekoff 2010, 
2013), a rapidly growing international and cross-disciplinary movement that stipulates that we need a conservation ethic that incorporates the protection of other animals as individuals: not just as members of populations of species, but valued in their own right.

The evolutionary underpinnings for the ethical behavior of compassion lie in the evolutionary processes that reward empathic adaptations (Goetz et al. 2010), but compassion can be practically defined as reflecting empathy in humans for non-human animals and a drive to alleviate harm and suffering. Unlike the dominant utilitarian approach to conservation that puts the cost of reaching conservation targets squarely on the shoulders of other animals, a compassionate ethic for conservation brings empathy into decision making alongside other values. It is not a rights position, but rather puts forward a scientific and evidence-based conceptual approach that stipulates that conservation initiatives should 'first do no harm' (Bekoff 2010). Not only is this important because of what we now know about the cognitive and emotional lives (consciousness and sentience) of other animals (Bekoff 2007, Bekoff and Pierce 2009), but also as a moral imperative for providing modern solutions for sharing space with nature and for fostering the possibility for diverse species to live in peaceful coexistence (Hinchliffe et al. 2005). Compassionate conservation allows for, but does not prescriptively dictate, outcomes where the interests of others supersede those of humans.

Examples where compassionate conservation principles are being applied have been steadily growing. Predation by carnivores is being successfully managed using fencing, fladry, and guard animals (Fox and Bekoff 2011), rather than through shooting, trapping and poisoning programs. Pack structures in non-exploited predator populations show evidence of declining rogue behavior and pack stability (Purcell 2010), thereby 
reducing negative interactions with humans (Bekoff and Jamieson 1996). Issues where species interfere with human endeavors are being solved by focusing on holistic ecological solutions and educational programs (e.g. restricting access to rubbish tips and putting roofs on city rubbish bins for ibis in Australia (Martin et al. 2012), and the use of fencing and local community engagement in the management of brown bears in Turkey (Ambarli and Bilgin 2008)). The costs of ignoring individual welfare in scientific programs are also gaining attention (Jewell 2013), as mainstream invasive techniques for studying animals are now known to be stressful and change species-typical behavior (Bekoff 2000). Human-wildlife conflicts can be exacerbated by a lack of science, transparency, and concern for harm to animals in decision-making (Artelle et al. 2014).

Compassionate conservation is challenging decision makers to have clear objectives where the lives of animals are affected. If interventions are necessary, the range of values of different stakeholders (human, non-human) should be articulated so that trade-offs may be transparently evaluated. Adaptive management principles are a must, where scientifically credible monitoring programs measure key performance indicators. Where harm to animals, either from an individual or species welfare perspective, is part of an intervention option, clear data are needed on the minimum number of animals that will be affected to achieve the desired outcome. Rating systems for harm exist for domestic animals and livestock, and should be integrated into conservation interventions targeting wildlife.

\section{Cause for optimism and a call to action}

Although millions of animals are killed in the name of conservation around the world each year, there is good cause to be optimistic. Acceptance of the intrinsic value of wild animals in nature, and an associated motivation to prevent harm to those animals, is 
often reported as an almost universal ethic among a wide variety of stakeholders (Butler and Acott 2007, Dubois and Fraser 2013). Compassionate conservation can help by providing solutions to conservation conflicts that have either proved intractable to resolve, or incur a heavy welfare cost to wild or captive individuals. That is not to say that individual welfare supersedes species or ecosystem welfare, only that we cannot continue to ignore individuals in conservation practice. By considering animal welfare alongside animal conservation it becomes possible to establish wildlife conservation frameworks that are explicitly oriented towards the management of the lives of individuals and their social groups and not just the species or population as a whole (Fraser 2010, Paquet and Darimont 2010). The word 'management' reflects the fact that in today's world, humans must interfere in the lives of other animals to resolve conflicts that inevitably arise from sharing space.

Despite clear progress, decision makers have only just begun to recognize the importance and utility of a compassionate and practical framework for conservation decision-making and triage. Difficult questions need to be asked about how best to engage with nature to resolve conservation conflicts. The aspirations underlying compassionate conservation have been long held by those interested in protecting nature, but as a movement, with a clear framework of operation, compassionate conservation is in its infancy. Factoring compassion into conservation presents a simple and morally acceptable approach to resolving issues of land sharing by utilizing the universal ethic of a concern for the suffering of others and attempts to alleviate it. Peaceful coexistence with other animals and their homes, grounded in compassion, is needed in an increasingly human-dominated world if society is to preserve and conserve nature in holistic and humane ways. 


\section{Acknowledgements}

We are indebted to the Born Free Foundation UK, particularly Will Travers and Chris

Draper, for supporting and promoting the conceptualization of compassionate conservation. Liv Baker, Dror Ben-Ami, Louise Boronyak and Kate Litten provided helpful discussion. The manuscript was greatly improved by comments from Paul Paquet and anonymous reviewers.

\section{References cited}

Ambarli H, Bilgin CC. 2008. Human-brown bear conflicts in Artvin, northeastern Turkey: encounters, damage, and attitudes. Ursus 19:146-153.

Artelle KA, Reynolds JD, Paquet PC, Darimont CT. 2014. When science-based management isn't. Science 343:1311.

Bandura A. 2007. Impeding ecological sustainability through selective moral disengagement. International Journal of Innovation and Sustainable Development 2:8-35.

Bekoff M. 2000. Field studies and animal models: the possibility of misleading inferences. Pages 1553-1559 in Balls M, Zeller A-Mv, Halder ME, eds. Progress in the reduction, refinement and replacement of animal experimentation, Elsevier.

---. 2002. The importance of ethics in conservation biology: let's be ethicists not ostriches. Endangered Species Update 19:23-26.

---. 2003. Minding animals, minding Earth: Old brains, new bottlenecks. Zygon 38:911-941.

---. 2007. The emotional lives of animals. New World Library.

---. 2010. First do no harm. Pages 24-25. New Scientist.

---, ed. 2013. Ignoring nature no more: the case for compassionte conservation. University of Chicago Press.

,--- 2014 . Rewilding our hearts: building pathways of compassion and coexistence. New World Library.

Bekoff M, Jamieson D. 1990. Cognitive ethology and applied philosophy the significance of an evolutionary biology of mind. Trends in Ecology \& Evolution 5:156-159.

--- 1996. Ethics and the study of carnivores: doing science while respecting animals. Pages 1545 in Gittleman JL, ed. Carnivore behaviour, ecology, and evolution, vol. 2. New York: Cornell University Press.

Bekoff M, Pierce J. 2009. Wild justice: the moral lives of animals. University of Chicago Press.

Ben-Ami D, Boom K, Boronyak L, Townend C, Ramp D, Croft DB, Bekoff M. 2014. The welfare ethics of the commercial killing of free-ranging kangaroos: an evaluation of the benefits and costs of the industry. Animal Welfare 23:1-10.

Bennitt HR, Dixon JS, Cahalane VH, Chase WW, McAtee WL. 1937. Statement of policy. Journal of Wildlife Management 1:1-2.

Bergstrom BJ, Arias LC, Davidson AD, Ferguson AW, Randa LA, Sheffield SR. 2014. License to kill: reforming federal wildlife control to restore biodiversity and ecosystem function. Conservation Letters 7:131-142.

Butler WF, Acott TG. 2007. An inquiry concerning the acceptance of intrinsic value theories of nature. Environmental Values 16:149-168.

Callicott JB. 1990. Whither conservation ethics? Conservation Biology 4:15-20. 
Davradou M, Namkoong G. 2001. Science, ethical arguments, and management in the preservation of land for grizzly bear conservation. Conservation Biology 15:570-577.

Doak DF, Bakker VJ, Goldstein BE, Hale B. 2013. What is the future of conservation? Trends in Ecology \& Evolution 29:77-81.

Dubois S, Fraser D. 2013. Rating harms to wildlife: a survey showing convergence between conservation and animal welfare views. Animal Welfare 22:49-55.

Dunlop BN. 2006. Conservation ethics. Society 43:13-18.

Ehrlich PR. 2002. Human natures, nature conservation, and environmental ethics. BioScience 52:31-43.

---. 2009. Ecoethics: now central to all ethics. Journal of Bioethical Inquiry 6:417-436.

Fox CH, Bekoff M. 2011. Integrating values and ethics into wildlife policy and management lessons from North America. Animals 1:126-143.

Fraser D. 1993. Assessing animal well-being: common sense, uncommon science.

---. 2010. Toward a synthesis of conservation and animal welfare science. Animal Welfare 19:121-124.

---. 2012. A "practical" ethic for animals. Journal of Agricultural \& Environmental Ethics 25:721746.

Fraser D, MacRae AM. 2011. Four types of activities that affect animals: implications for animal welfare science and animal ethics philosophy. Animal Welfare 20:581-590.

Gaston KJ, Fuller RA. 2007. Biodiversity and extinction: losing the common and the widespread. Progress in Physical Geography 31:213-225.

Gelcich S, Kaiser MJ, Castilla JC, Edwards-Jones G. 2008. Engagement in co-management of marine benthic resources influences environmental perceptions of artisanal fishers. Environmental Conservation 35:36-45.

Goetz JL, Keltner D, Simon-Thomas E. 2010. Compassion: an evolutionary analysis and empirical review. Psychological Bulletin 136:351-374.

Harrop SR. 1999. Conservation regulation: a backward step for biodiversity? Biodiversity and Conservation 8:679-707.

Hinchliffe S, Kearnes MB, Degen M, Whatmore S. 2005. Urban wild things: a cosmopolitical experiment. Environment and Planning D: Society and Space 23:643-658.

Jepson P, Canney S. 2003. Values-led conservation. Global Ecology and Biogeography 12:271274.

Jewell Z. 2013. Effect of monitoring technique on the quality of conservation science. Conservation Biology 27:501-508.

Kareiva P, Marvier M. 2012. What is conservation science? BioScience 62:962-969.

Larson BMH. 2007. An alien approach to invasive species: objectivity and society in invasion biology. Biological Invasions 9:947-956.

Lejano RP, Fernandez de Castro F. 2013. Norm, network, and commons: the invisible hand of community. Environmental Science \& Policy.

Leopold A. 1949. A sand county almanac: and sketches here and there. Oxford University Press.

Littin KE. 2010. Animal welfare and pest control: meeting both conservation and animal welfare goals. Animal Welfare 19:171-176.

Lorimer J. 2007. Nonhuman charisma. Environment and Planning D: Society and Space 25:911932.

Martin J, French K, Major R. 2012. Behavioural adaptation of a bird from transient wetland specialist to an urban resident. PLoS One 7:e50006.

Minteer BA, Collins JP. 2005. Why we need an "ecological ethics". Frontiers in Ecology and the Environment 3:332-337.

Naess A. 1973. The shallow and the deep, long-range ecology movement. A summary. Inquiry 16:95-100.

Nagy K, Johnson PDI, eds. 2013. Trash animals: how we live with nature's filthy, feral, invasive, and unwanted species University of Minnesota Press.

O'Sullivan S. 2011. Animals, equality and democracy. Palgrave Macmillan. 
Paquet PC, Darimont CT. 2010. Wildlife conservation and animal welfare: two sides of the same coin? Animal Welfare 19:177-190.

Purcell B. 2010. Dingo. CSIRO Publishing.

Ramp D. 2013. Bringing compassion to the ethical dilemma in killing kangaroos for conservation. Journal of Bioethical Inquiry 10:267-272.

Redpath SM, et al. 2013. Understanding and managing conservation conflicts. Trends in Ecology \& Evolution 28:100-109.

Regan T. 1983. The case for animal rights. University of California Press.

Routley R. 1973. Is there a need for a new, an environmental, ethic? Pages 205-210. 15th World Congress of Philosophy. Varna, Bulgaria: Sofia Press.

Soulé ME. 1985. What is conservation biology? BioScience 35:727-734.

Tisdell C, Nantha HS. 2007. Comparison of funding and demand for the conservation of the charismatic koala with those for the critically endangered wombat Lasiorhinus krefftii. Biodiversity and Conservation 16:1261-1281.

Treves A, Karanth KU. 2003. Human-carnivore conflict and perspectives on carnivore management worldwide. Conservation Biology 17:1494-1499.

Vucetich JA, Nelson MP. 2007. What are 60 warblers worth? Killing in the name of conservation. Oikos 116:1267-1278.

---. 2013. The infirm ethical foundations of conservation in Bekoff M, ed. Ignoring nature no more: the case for compassionate conservation. Chicago: University of Chicago Press.

Webb TJ, Raffaelli D. 2008. Conversations in conservation: revealing and dealing with language differences in environmental conflicts. Journal of Applied Ecology 45:1198-1204.

Yeo JH, Neo H. 2010. Monkey business: human-animal conflicts in urban Singapore. Social \& Cultural Geography 11:681-699. 